\title{
Epstein-Barr Virus-Related Lymphoproliferative Disorder Caused by the Use of Antithymocyte Globulin and Cyclosporine for Aplastic Anemia
}

\author{
Shoji Suzuki ${ }^{a}$, Torahiko Jinta ${ }^{a}$, Naoki Nishimura ${ }^{a, b}$
}

\begin{abstract}
A 70-year-old woman with aplastic anemia treated by antithymocyte globulin (ATG), cyclosporine and prednisolone visited our hospital complaining of fever and general fatigue for a week. A chest computed tomography (CT) scan showed consolidation in both lungs, and histological analysis of the lung tissue showed Epstein-Barr virus-positive diffuse large B-cell lymphoma. We diagnosed immunodeficiency-associated lymphoproliferative disorder, and consolidation of the lung was reduced after the cessation of cyclosporine. We should consider the possibility of malignant lymphoma when CT scan showed multiple patchy consolidations with random pattern in both lungs as septic pulmonary emboli in patients with immunosuppressive treatment.
\end{abstract}

Keywords: Epstein-Barr virus; Lymphoproliferative disorder; Antithymocyte globulin; Cyclosporine; Septic pulmonary emboli

\section{Introduction}

Immunodeficiency-associated lymphoproliferative disorders are caused by the use of immunosuppressants, mostly methotrexate or a tumor necrosis factor- $\alpha$-neutralizing agent such as infliximab [1]. Lymphoproliferative disorders are often caused by the suppression of T-cell activity by immunosuppressants [2]. It is extremely unusual for antithymocyte globulin (ATG) and cyclosporine to cause lymphoproliferative disorders except after transplantation.

In the case reported here, we present a lymphoprolifera-

Manuscript accepted for publication March 31, 2014

a Division of Pulmonary Medicine, St. Luke's International Hospital, 9-1, Akashi-cho, Chuo City, Tokyo 104-8560, Japan

${ }^{\mathrm{b}}$ Corresponding author: Naoki Nishimura, Division of Pulmonary

Medicine, St. Luke's International Hospital, 9-1, Akashi-cho, Chuo

City, Tokyo 104-8560, Japan. Email: nina@luke.ac.jp

doi: http://dx.doi.org/10.14740/jmc1769w tive disorder in the lungs caused by ATG and cyclosporine that were administered for the treatment of aplastic anemia. To our knowledge, case report of pulmonary lymphoma caused by ATG and cyclosporine outside of the post-transplantation setting is very rare.

\section{Case Report}

A 70-year-old woman with aplastic anemia treated with ATG ( 8 months ago, $2.5 \mathrm{mg} / \mathrm{kg}$ for 5 days), prednisolone (started on $15 \mathrm{mg} 8$ months ago, with dose tapered to $7.5 \mathrm{mg}$ ) and cyclosporine (started 6 years ago, with trough levels maintained between 150 and $200 \mathrm{ng} / \mathrm{mL}$ ) visited our hospital complaining of fever and general fatigue for a week. Although no respiratory symptoms and no abnormal physical findings were observed, chest radiograph and computed tomography (CT) scan showed patchy consolidation in both lungs (Fig. $1,2)$. We diagnosed pneumonia or septic emboli and started antibiotics (laboratory findings are shown in Table 1). We started treatment with amoxicillin/clavulanate and moxifloxacin and switched to cefepime, clindamycin and minocycline

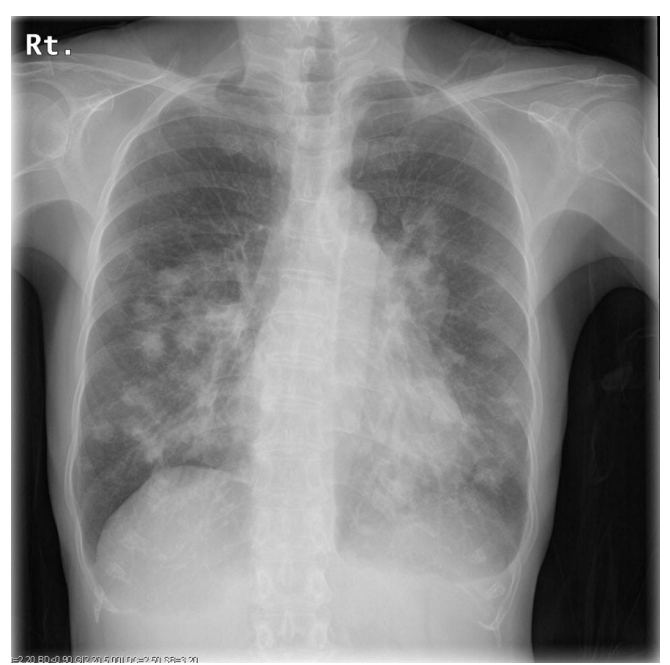

Figure 1. Chest radiograph on admission showing consolidation of the bilateral lungs. 

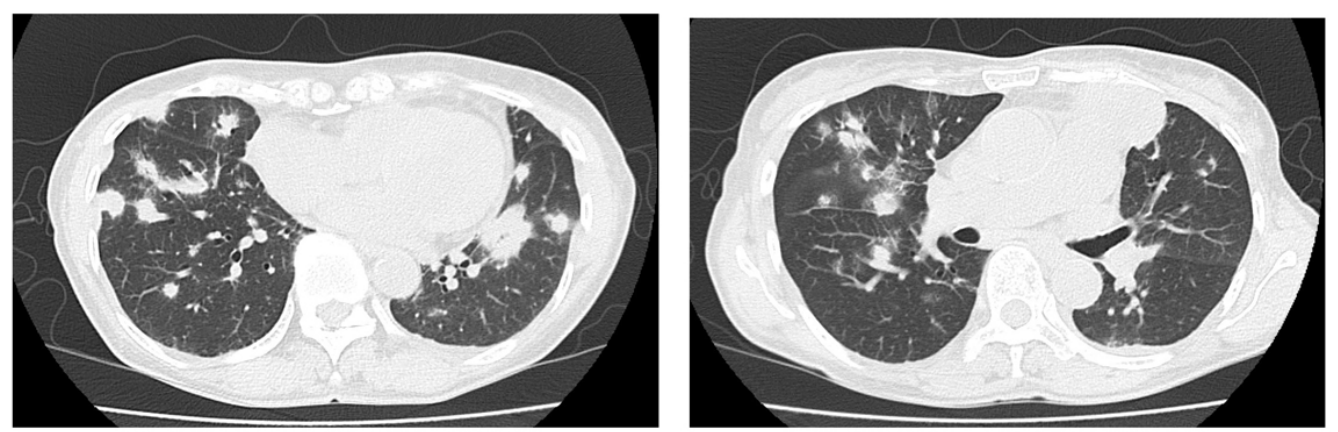

Figure 2. Chest computed tomography scan showing multiple patchy consolidation and nodules in both lungs.

because of persistent fever, but the fever continued and the chest radiograph showed aggravated consolidation and left pleural effusion after a week of antibiotics therapy.

We performed transthoracic needle lung biopsy of a nodule. The cultured specimen showed no evidence of bacterial or fungal infection, and histological analysis of the specimen showed Epstein-Barr virus (EBV)-positive diffuse large Bcell lymphoma (DLBCL) (Fig. 3). We diagnosed immunodeficiency-associated lymphoproliferative disorder resulting from treatment with ATG and cyclosporine. The serum EBV

Table 1. Laboratory Data on Admission

\begin{tabular}{|c|c|c|c|c|c|}
\hline \multicolumn{2}{|c|}{ Hematology } & \multicolumn{2}{|l|}{ Biochemistry } & \multicolumn{2}{|l|}{ Serology } \\
\hline WBC & $13,100 / \mu \mathrm{L}$ & Alb & $3.0 \mathrm{~g} / \mathrm{dL}$ & CRP & $2.78 \mathrm{mg} / \mathrm{dL}$ \\
\hline Myelo & $1.0 \%$ & BUN & $33.1 \mathrm{~g} / \mathrm{dL}$ & $\operatorname{IgG}$ & $756 \mathrm{mg} / \mathrm{dL}$ \\
\hline Stab & $1.5 \%$ & $\mathrm{Cr}$ & $1.23 \mathrm{mg} / \mathrm{dL}$ & $\operatorname{IgA}$ & $307 \mathrm{mg} / \mathrm{dL}$ \\
\hline Seg & $69.5 \%$ & T-Bil & $0.6 \mathrm{mg} / \mathrm{dL}$ & $\operatorname{IgM}$ & $89 \mathrm{mg} / \mathrm{dL}$ \\
\hline Eosino & $0.5 \%$ & ALP & $312 \mathrm{U} / \mathrm{L}$ & Cyclosporine & $54.4 \mathrm{ng} / \mathrm{mL}$ \\
\hline Ly & $17.0 \%$ & $\mathrm{LDH}$ & $272 \mathrm{U} / \mathrm{L}$ & sIL-2R & $6040 \mathrm{U} / \mathrm{mL}$ \\
\hline Mono & $10.5 \%$ & AST & $17 \mathrm{U} / \mathrm{L}$ & & \\
\hline $\mathrm{RBC}$ & $339 \times 10^{4} / \mu \mathrm{L}$ & ALT & $13 \mathrm{U} / \mathrm{L}$ & $\begin{array}{l}\text { Arterial blood } \\
\left(\mathrm{FiO}_{2} 0.24\right)\end{array}$ & analysis \\
\hline $\mathrm{Hb}$ & $9.9 \mathrm{~g} / \mathrm{dL}$ & $\gamma$-GTP & $83 \mathrm{U} / \mathrm{L}$ & $\mathrm{pH}$ & 7.450 \\
\hline Hct & $29.0 \%$ & $\mathrm{CK}$ & $23 \mathrm{U} / \mathrm{L}$ & $\mathrm{PaCO}_{2}$ & $33.3 \mathrm{mmHg}$ \\
\hline \multirow[t]{6}{*}{ Plt } & $25.5 \times 10^{4} / \mu \mathrm{L}$ & $\mathrm{Ca}$ & $8.8 \mathrm{mg} / \mathrm{dL}$ & $\mathrm{PaO}_{2}$ & $70.8 \mathrm{mmHg}$ \\
\hline & & $\mathrm{Na}$ & $135 \mathrm{mEq} / \mathrm{L}$ & $\mathrm{HCO}_{3}^{-}$ & $22.8 \mathrm{mEq} / \mathrm{L}$ \\
\hline & & K & $4.3 \mathrm{mEq} / \mathrm{L}$ & Lactate & $1.0 \mathrm{mmol} / \mathrm{L}$ \\
\hline & & $\mathrm{Cl}$ & $101 \mathrm{mEq} / \mathrm{L}$ & & \\
\hline & & Glu & $187 \mathrm{mg} / \mathrm{dL}$ & & \\
\hline & & $\beta$-D glucan & $5.7 \mathrm{pg} / \mathrm{mL}$ & & \\
\hline
\end{tabular}

Abbreviations: sIL-2R, soluble interleukin-2 receptor. 

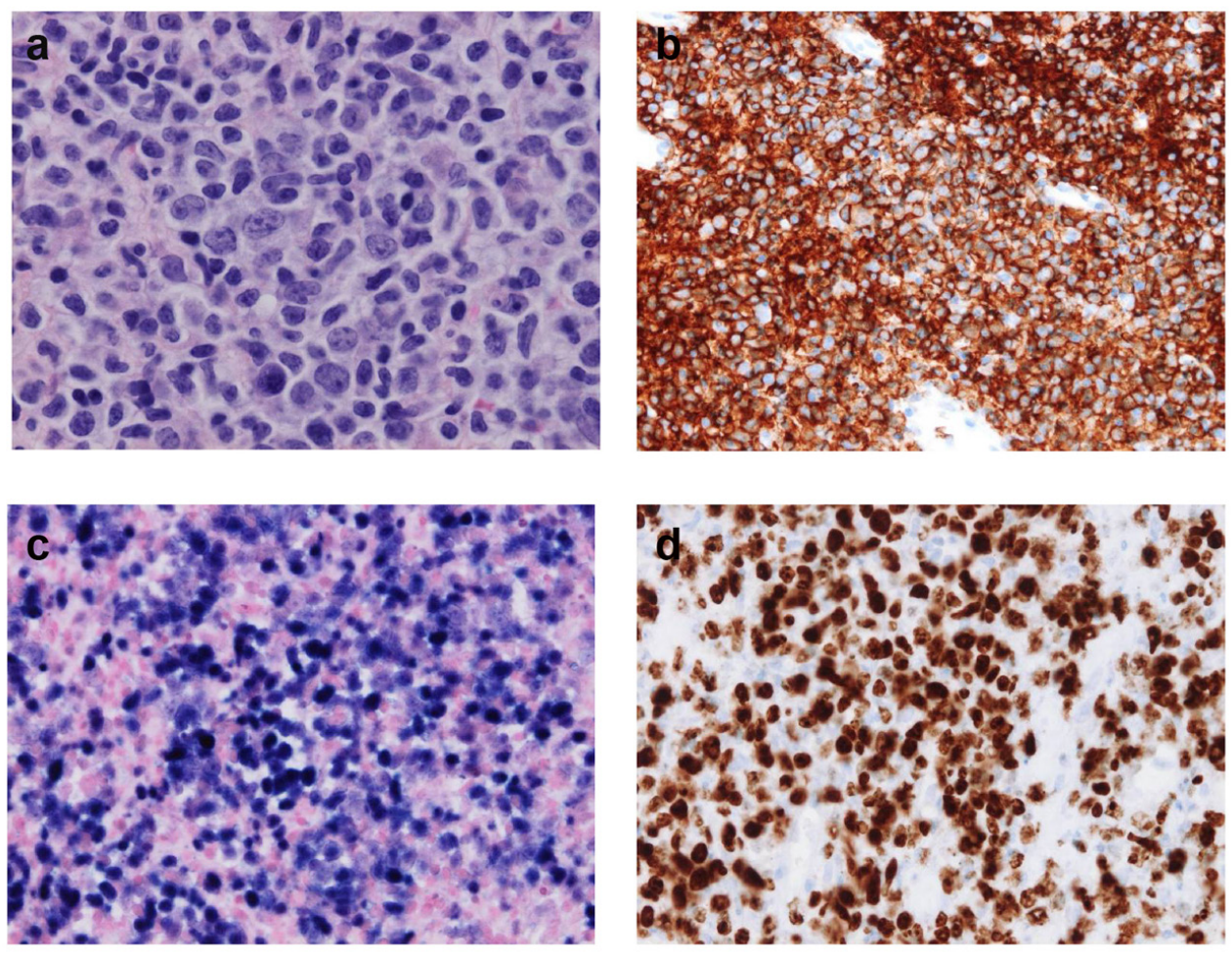

Figure 3. Lung biopsy. (a) Hematoxylin-eosin (HE) stain ( $\times 40)$ shows large, blastic, atypical lymphoid cells. (b) Most cells are strongly stained for CD20. (c) Epstein-Barr virus (EBV)-encoded RNA in situ hybridization shows the presence of EBV in lymphoid cells. (d) Nuclear Ki-67 staining shows a high Ki-67 labeling index (over 80\%).

DNA load was $6.7 \times 10^{3}$ copies $/ 10^{6}$ cells. A whole-body trunk CT scan with contrast enhancement showed no other region of lymphadenopathy or nodule. Bone marrow aspiration and biopsy showed bone marrow involvement of lymphoma. After the diagnosis, we discontinued cyclosporine and antibiotics therapy. Because the chest radiograph showed regression of consolidation and the fever had declined by 2 weeks after discontinuation of the immunosuppressant (Fig. 4), the patient was discharged from the hospital.

\section{Discussion}

We report here a case of a 70-year-old patient with lymphoproliferative disorder in the lungs caused by immunosuppressive treatment with ATG and cyclosporine for aplastic anemia. Histological investigation showed EBV-positive DLBCL, and we administered ATG, cyclosporine and prednisolone, although not for transplantation. Primary pulmonary lymphoma of the lungs is a rare disorder; the incidence of primary pulmonary lymphoma is $0.3 \%$ of all primary lung neoplasms and less than $0.5 \%$ of all lymphomas [3]. The most common type of primary pulmonary lymphoma, accounting for approximately $70 \%$, is marginal zone lymphoma of mucosa-associated lymphoid tissue, but it is reported that most human immunodeficiency virus-positive patients have highgrade, EBV-positive DLBCL [3]. Patients with EBV-positive immunodeficiency-associated lymphoproliferative disorder in the lung may tend to have DLBCL. Moreover, iatrogenic lymphoproliferative disorder, except in the post-transplantation setting, is extremely rare. To our knowledge, this is the first report in the English literature about immunodeficiencyassociated lymphoproliferative lung disorder in relation to EBV outside of a post-transplantation setting.

It is known that ATG use in a preparative regimen of bone marrow transplantation confers a high risk of posttransplant lymphoproliferative disorders, especially EBV-related B-cell lymphoproliferative disorder [4]. This case was not a post-transplant lymphoproliferative disorder, but ATG may have contributed to the development of the lymphoproliferative disorder because EBV proliferation was observed in this case. According to previous studies, the time between ATG administration (combined with cyclosporine in most cases) and the onset of the lymphoproliferative disorder was 1 - 20 months, indicating the contribution of ATG in these cases $[5,6]$.

Because the chest radiograph showed resolution of the consolidation of the lungs and soluble interleukin-2 receptor decreased after discontinuation of cyclosporine, cyclosporine may also play some role in the development of lympho- 

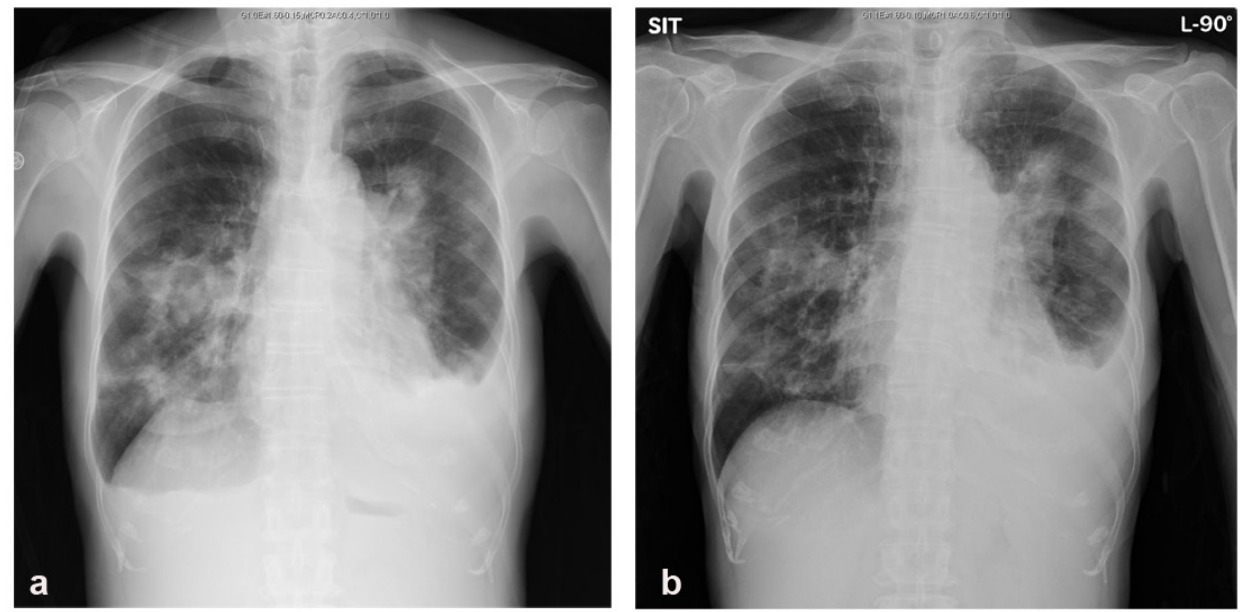

Figure 4. Chest radiographs showing consolidation of lungs was decreased by the cessation of cyclosporine. (a) Before discontinuation of cyclosporine. (b) Fourteen days after discontinuation of cyclosporine.

proliferative disorder.

We should consider the possibility of malignant lymphoma when CT scan showed multiple patchy consolidations with random pattern in both lungs as septic pulmonary emboli in patients with immunosuppressive treatment.

In conclusion, after treatment of aplastic anemia with ATG, cyclosporine and prednisolone, EBV-related lymphoproliferative disorder may develop, although rarely. We should be aware of this rare disorder as well as infectious disease in immunosuppressive patients.

\section{Conflict of Interests}

The authors declare that there is no conflict of interests regarding the publication of this paper.

\section{References}

1. Hoshida Y, Xu JX, Fujita S, Nakamichi I, Ikeda J, Tomita Y, Nakatsuka S, et al. Lymphoproliferative disorders in rheumatoid arthritis: clinicopathological analysis of 76 cases in relation to methotrexate medication. J Rheu- matol. 2007;34(2):322-331

2. Wakabayashi S, Ohashi K, Hanajiri R, Kobayashi T, Yamashita T, Akiyama H, Sakamaki H. Rapidly progressive Epstein-Barr virus-associated lymphoproliferative disorder unpredictable by weekly viral load monitoring. Intern Med. 2010;49(10):931-935.

3. William J, Variakojis D, Yeldandi A, Raparia K. Lymphoproliferative neoplasms of the lung: a review. Arch Pathol Lab Med. 2013;137(3):382-391.

4. Bhatia S, Ramsay NK, Steinbuch M, Dusenbery KE, Shapiro RS, Weisdorf DJ, Robison LL, et al. Malignant neoplasms following bone marrow transplantation. Blood. 1996;87(9):3633-3639.

5. Sugimoto-Sekiguchi H, Tashiro H, Shirasaki R, Arai T, Yamamoto T, Oka Y, Akiyama N, et al. Colonic EBV-Associated Lymphoproliferative Disorder in a Patient Treated with Rabbit Antithymocyte Globulin for Aplastic Anemia. Case Rep Gastrointest Med. 2012;2012:395801.

6. Suzuki Y, Niitsu N, Hayama M, Katayama T, Ishii R, Osaka M, Miyazaki K, et al. Lymphoproliferative disorders after immunosuppressive therapy for aplastic anemia: a case report and literature review. Acta Haematol. 2009;121(1):21-26. 